\title{
DESAFIOS ENFRENTADOS PELOS ENFERMEIROS PARA IMPLEMENTAÇÃO \\ DA EDUCAÇÃO PERMANENTE EM SAÚDE NA ESTRATÉGIASAÚDE DA \\ FAMÍLIA
}

Challenges faced by nurses for implementation of permanent health education in family health strategy

Camila Martins $^{1}$, Maria Tereza Soratto ${ }^{2}$

${ }^{1}$ Enfermeira. Especialista em Gestão da Atenção Básica em Saúde - UNESC -

Universidade do Extremo Sul de Santa Catarinense. Email:

millla sc@hotmail.com.mailto.

${ }^{2}$ Enfermeira. Mestre em Educação. Professora do Curso de Pós Graduação

Especialização em Gestão da Atenção Básica de Saúde - UNESC - Universidade do

Extremo Sul de Santa Catarina - Criciúma - SC - Brasil. Email: guiga@unesc.net

\section{Endereço para correspondência:}

Maria Tereza Soratto. Departamento de Enfermagem - Unidade Acadêmica da Saúde - UNASAU - UNESC. Av. Universitária, 1105. Criciúma - SC - Bairro

Universitário. CEP - 88806-000. Email: guiga@unesc.net. 


\section{Resumo}

A Educação Permanente em Saúde é uma estratégia para a construção de novas práticas em saúde e enfermagem. Pesquisa com objetivo de identificar os desafios enfrentados pelos enfermeiros para implementação da Educação Permanente em Saúde (EPS) na Estratégia Saúde da Família (ESF). Pesquisa de abordagem qualitativa, descritiva, exploratória e de campo. Aplicou-se questionário semiestruturado com 08 enfermeiras da ESF de um município do Extremo Sul de Santa Catarina.A análise e interpretação dos dados qualitativos foram realizadas pela análise de conteúdo, a partir da categorização dos dados. Os resultados mostraram que não há esse entendimento por parte das enfermeiras de como funciona o organização da educação permanente em saúde na estratégia saúde da família, há um desconhecimento sobre o verdadeiro significado e as práticas que envolvem aPolítica de Educação Permanente em Saúde. A Educação Permanente em Saúde, mesmo sendo uma política pública, ainda é realizada de forma fragmentada e pouco flexível. É necessário que os profissionais tenham clareza da direcionalidade dessa política para a transformação das práticas de saúde.

Palavras Chaves: Educação em Saúde; Estratégia Saúde da Família; Educação Continuada em Enfermagem.

\section{Abstract}

The Continuing Health Education is a strategy for the construction of new practices in health and nursing. This research aims to identify the challenges faced by nurses for implementation of Continuing Health Education in the Family Health Strategy. qualitative research, descriptive, exploratory and field. Semi-structured questionnaire was applied to 08 nurses of the FHT of a municipality in the extreme south of Santa Catarina. The analysis and interpretation of qualitative data were performed by content analysis, from the categorization of data. The results showed that there is this understanding by nurses of how the organization of continuing education in health in the family health strategy, there is a lack of knowledge about the true meaning and practices involving the Policy of Permanent Education in Health. 
Education Standing in health, even as a public policy, it is still held in a fragmented and inflexible manner. It is necessary that the professionals are clear directionality of this policy for the transformation of health practices.

Key Words: Health Education; Family Health Strategy; Education, Nursing, Continuing.

\section{INTRODUÇÃO}

A Política Nacional de Educação Permanente em Saúde foi instituída pela portaria 198/GM de 13 de fevereiro de 2004, e atualmente é orientada pela Portaria GM/MS n. 1.996/07, a qual estabelece as diretrizes para a sua implantação e implementação. Apresenta como estratégia de gestão a educação permanente na reorganização do sistema de ensino em saúde. Funciona como dispositivo de aproximação entre o cotidiano do profissional do SUS e as necessidades da população. Há mais de duas décadas, o Brasil vem redefinindo a estrutura e o perfil do sistema de saúde 1 .

A consolidação do SUS tem exigido dos gestores de saúde, nas diferentes esferas de governo, a identificação e definição de estratégias para resolução dos problemas indicando a necessidade do fortalecimento das práticas de gestão e controle social nesse campo, bem como a mudança nos processos de formação em saúde².

No SUS, os lugares de produção de cuidado são ao mesmo tempo cenários de produção pedagógica. Educar no trabalho e educar o profissional para o mercado de trabalho é um pressuposto da proposta da Educação Permanente em Saúde.Isso nos faz refletir que não somente à Educação fica a responsabilidade de formar cidadãos de opinião, de conhecimento técnico/científico, competem a nós, profissionais da área da saúde, gestores em nossos ambientes de trabalho tornar nosso dia a dia constante ambiente de aprendizado, uma vez que trabalho, ensino e aprendizagem misturam-se nos cenários de produção da saúde ${ }^{1}$.

Segundo Portaria ㄲo 278 de 27 de fevereiro de 2014, o Plano de Educação Permanente em Saúde, deve ser construído de maneira coletiva, 
proporcionando amplo debate e tendo por base o planejamento participativo e ascendente. O processo de discussão e construção do PEP-MS dar-se-á com a participação efetiva dos trabalhadores, considerando a análise estratégica do contexto do Ministério da Saúde e a intencionalidade das políticas públicas em saúde. As ações de educação do PEP-MS devem incluir todos os trabalhadores atuantes no Ministério da Saúde, tendo em perspectiva a diversidade de vínculos existentes e a legislação vigente.As ações de educação do PEP-MS devem ocorrer, preferencialmente, por meio dos espaços coletivos de trabalho, no âmbito das equipes multiprofissionais.Deve ser priorizada a forma coletiva de aprendizagem orientada para as equipes que atuam em processos de trabalho compartilhados, suprindo as lacunas de conhecimento identificadas no cotidiano ${ }^{3}$.

A Educação Permanente baseia-se no ensino problematizador e na aprendizagem significativa, onde os problemas presentes na realidade do dia a dia na saúde são objetivo de discussão, análise e reflexão e para os quais se buscam soluções, mudanças, respostas e produção de conhecimento. Este processo leva em consideração as experiências, as vivências, e os conhecimentos anteriores para a construção de novos conhecimentos. A educação permanente em saúde expressa uma opção político-pedagógica, não apenas didático-pedagógico 4 .

Para a 'educação permanente em saúde', não existe a educação de um ser que sabe para um ser que não sabe, o que existe, como em qualquer educação crítica e transformadora, é a troca e o intercâmbio, as deve ocorrer também 0 'estranhamento' de saberes e a 'desacomodação' com os saberes e as práticas que estejam vigentes em cada lugar. Isto não quer dizer que aquilo que já sabemos ou já fazemos está errado, quer dizer que, para haver ensino aprendizagem, temos de entrar em um estado ativo de 'perguntação', constituindo uma espécie de tensão entre o que já se sabe e o que há por saber ${ }^{4}$.

Uma condição indispensável para um aluno, trabalhador de saúde, gestor ou usuário do sistema de saúde mudar ou incorporar novos elementos à sua prática e aos seus conceitos é o desconforto com a realidade naquilo que deixamos a desejar de integralidade e de implicação com os usuários. A necessidade de mudança, transformação ou crescimento vem da percepção de que a maneira vigente de fazer ou de pensar alguma coisa está insatisfatória ou insuficiente em dar 
conta dos desafios do trabalho em saúde. Esse desconforto funciona como um estranhamento da realidade, sentindo que algo está em desacordo com as necessidades vividas ou percebidas pessoalmente, coletivamente ou institucionalmente ${ }^{4}$.

No mesmo período histórico de implantação da Política Nacional de Educação Permanente em Saúde (PNEPS), em 2003 aPolítica Nacional de Humanização de Atenção e da Gestão do SUS (PNH) inicia suas ações, após a experiência do Programa Nacional de Humanização da Atenção Hospitalar (PNHAH) que atuou de 2000 a 2002 na área hospitalar da saúde brasileira. Esta política pública pretende transversalizar a humanização com o intuito de fortalecer o Sistema Único de Saúde, promovendo a inclusão dos diferentes sujeitos envolvido no processo ${ }^{5}$.

A humanização implica em aumentar a co-responsabilidade dos profissionais do SUS, no processo de trabalho da saúde. A humanização perpassa a mudança na cultura da atenção e da gestão dos processos de trabalho, com a atenção e o vínculo compartilhado, garantindo os direitos dos usuários e seus familiares, estimulando a participação da família como sujeito do cuidado por meio de ação de controle social. Humanização também se relaciona a qualidade de vida no trabalho, com melhores condições e dignidade no processo de trabalho com a possibilidade do profissional ser criador de novas ações e participante como cogestor deste processo de mudança ${ }^{5}$.

A Política Nacional de Humanização nos apresenta Diretrizes gerais para sua implementação, são diretrizes específicas da Atenção Básica: elaborar projetos de saúde individuais e coletivos para usuários e sua rede social, considerando as políticas intersetoriais e as necessidades de saúde; incentivar práticas promocionais de saúde; estabelecer formas de acolhimento e inclusão do usuário que promovam a otimização dos serviços, o fim das filas, a hierarquização de riscos e o acesso aos demais níveis do sistema; comprometer-se com o trabalho em equipe, de modo a aumentar o grau de corresponsabilidade, e com a rede de apoio profissional, visando a maior eficácia na atenção em saúde 5 .

Segundo a portaria ํo 278 de 27 de fevereiro de 2014 onde diz que educação permanente em saúde é um processo de aprendizado no trabalho, onde o 
aprender e o ensinar se incorporam ao cotidiano das organizações e ao trabalho, baseando-se na aprendizagem significativa e na possibilidade de transformar as práticas dos trabalhadores da saúde, tendo como um dos princípios da política de educação permanente em saúde a articulação entre educação e trabalho no SUS, por isso, considera-se como importante a aplicação dessa política dentro dos serviços de saúde da atenção básica, mais precisamente nos momentos de reuniões de equipe, onde a equipe multiprofissional tem a oportunidade de dialogar, sugerir, identificar, planejar e fomentar reflexões críticas dos processos de trabalho no SUS ${ }^{3}$.

A proposta nos faz refletir e nos leva a uma provocação de mudança de atitudes e pensamentos que devemos ter diante de nossos enfrentamentos no processo de trabalho. Não conseguimos fazer isso sozinho, uma das propostas da Educação Permanente em Saúde e da Polícia Nacional de Humanização é se trabalhar em grupo e em equipe. Não podemos mecanizar a assistência prestada, precisamos utilizar as ferramentas disponíveis para a humanização do cuidado. Uma forma de se trabalhar e de se pensar Educação Permanente em Saúde e Humanização é a criação de núcleos de educação permanente em saúde e humanização (NEPSHU) nos municípios. Esses núcleos são formados por trabalhadores, gestores, usuários que estão dispostos a buscar novos conhecimentos, novos desafios e fazer pensar saúde e educação para todos. Humanização implica em investir no trabalhador para que ele tenha condições de prestar atendimento humanizado.

Através do decreto no 180/2014 de 23 de outubro de $2014^{6}$, fica instituído do município de Içara o Núcleo de Educação Permanente em Saúde - NEPSHU, com a finalidade de estabelecer diretrizes e estratégias para implementação da Política de Educação Permanente em Saúde e Humanização da Atenção Básica e da Gestão do SUS no âmbito da Secretaria Municipal de Saúde. O núcleo é um espaço de diálogo entre os diferentes atores sociais (trabalhadores, ensino, gestão, usuários) e os diversos níveis de atenção, setores e coletivos (comitês, comissões, câmaras técnicas, grupos de trabalho entre outros) das políticas de saúde e educação, instituído como uma instância colegiada com a finalidade de elaborar, planejar, apoiar e executar de modo articulado as propostas que envolvem ações de educação e humanização na saúde. 
O Núcleo de Educação Permanente em Saúde tem como objetivos: ampliar a articulação interna nos municípios em relação às questões regionais e municipais sobre a EPS e Humanização; otimizar os recursos financeiros destinados as ações de educação permanente em saúde; estimular a corresponsabilização entre os trabalhadores, gestores, ensino e usuários na qualificação dos serviços; aproximar e fortalecer as políticas de educação permanente em saúde e Humanização em âmbito locorregional; organizar processos cogeridos de avaliação das ações em saúde; fortalecer as Redes Integradas de Atenção à Saúde. Ainda busca contribuir para o desenvolvimento em âmbito municipal dos compromissos firmados nos Pactos da Saúde, envolvendo a educação permanente em saúde e Humanização como estratégias; articular as demandas, arranjos e necessidades da Educação Permanente em Saúde e Humanização em todos os níveis de atenção e gestão da saúde; apoiar a gestão, no sentido da qualificação dos processos de trabalho, promovendo a indissociabilidade entre a atenção e a gestão;promover a aproximação entre atenção e a gestão do trabalho em defesa do SUS ${ }^{6}$.

As equipes de saúde da família do município de Içara disponibilizam de uma hora e meia por semana de momentos destinados a educação permanente em saúde. São momentos de reflexões, de se colocar em análise com relação ao processo de trabalho, de novos aprendizados, de aperfeiçoamentos. Pela dificuldade de estar participando de todos esses momentos como profissional da gestão, e por desconhecer o que realmente a equipe realizade processo de trabalho nesses momentos é que a partir destas experiências realizaremos uma pesquisa com o enfoque nos desafios vivenciados pelos enfermeiros para a implementação desta proposta nos momentos de reunião de equipe, além de conhecer a organização da educação permanente em saúde na estratégia saúde da família.

Diante dessas questões surgiram inquietações referentes aos momentos destinados à educação permanente em saúde aos profissionais da atenção básica. O que realmente é trabalhado nesses momentos? Qual a motivação desses profissionais? Qual o conhecimento dos profissionais com relação à política de educação permanente?

Considera-se que os desafios enfrentados pelos enfermeiros para implementação da educação permanente em saúde (EPS) na Estratégia Saúde da 
Família (ESF) estão relacionados ao desconhecimento da Política Nacional de Educação Permanente em Saúde e Política Nacional de Humanização pelos enfermeiros; falta de percepção e conhecimento por parte dos enfermeiros de que algumas atividades de educação permanente que são realizadas com a equipe onde não identificam tal ação como inclusa naeducação permanente em saúde; desmotivação de alguns profissionais e/ou falta de perfil para o processo de trabalho voltado a Educação Permanente em Saúde.

A rede de serviço conta com o Núcleo de Educação Permanente em Saúde - NEPSHU, que organizou uma proposta de Educação Permanente para o fortalecimento da Politica de Educação Permanente em Saúde e Política Nacional de Humanização.

Nesta perspectiva este estudo tem por objetivo identificar os desafios enfrentados pelos enfermeiros para implementação da Educação Permanente em Saúde (EPS) na Estratégia Saúde da Família (ESF).

\section{MATERIAL E MÉTODOS}

Pesquisa de abordagem qualitativa, descritiva, exploratória e de campo. Aplicou-se questionário semi-estruturado com 08 enfermeiros da ESFde um município do Extremo Sul de Santa Catarina.Utilizaram-se como critérios de inclusão: enfermeiros atuantes na Estratégia Saúde da Família (ESF); aceitação para participar da Pesquisa segundo Resolução 510/2016 e assinar o Termo de Consentimento Livre e Esclarecido (TCLE).

A análise e interpretação dos dados qualitativos foram realizadas pela análise de conteúdo, a partir da categorização dos dados. Categoria refere-se a um conceito que abrange elementos ou aspectos com características comuns ou que se relacionam entre si, são estabelecidas para classificar os eventos. Categorizar é agrupar elementos, ideias ou expressões em torno de um conceito ${ }^{8,9}$.

Dentre os aspectos éticos o consentimento livre e esclarecido prevê a anuência do sujeito da pesquisa após a explicação completa sobre a natureza da mesma, seus objetivos, métodos, benefícios previstos e potenciais riscos que possam acarretar, formulada em termo de consentimento, autorizando sua 
participação na pesquisa. Na pesquisa utilizou-se um termo de consentimento livre e esclarecido, informando aos participantes os objetivos, métodos, direito de desistir da mesma e sigilo em relação à pesquisa.Para preservar o sigilo e o anonimato dos participantes da pesquisa, de acordo com as diretrizes e normas regulamentadoras da Resolução 510/20167, utilizou-se designação de cores para os enfermeiros: Roxa, Azul, Rosa, Verde, Amarelo, Laranja, Vermelho, Marrom.

A pesquisa foi aprovada pelo Comitê de Ética em Pesquisa da UNESC pelo Projeto oㅜ 1.305.651/2015.

\section{RESULTADOS E DISCUSSÃO}

A coordenação de atenção básica do município possui um cronograma quinzenal de reuniões de enfermeiros onde em uma dessas reuniões participou-se e realizou-se a exposição da proposta do trabalho apresentado e através do consentimento dos 18 enfermeiros iniciou-se a aplicação do questionário. Foi entregue para os 18 enfermeiros o questionário com um prazo de entrega de 20 dias para o retorno do mesmo com as informações necessárias para dar continuidade à proposta. Após esse período recebeu-se o retorno de 08 dos 18 questionários. As participantes do estudo foram identificadas na pesquisa por nomes de cores.

\section{Perfil dos enfermeiros}

Quanto ao perfil dos enfermeiros percebe-se que todos os entrevistados são do sexo feminino (08 enfermeiras). Com relação à idade50\% possuem entre 25 a 30 anos e $50 \%$ entre 31 a 39 anos. Quando perguntado com relação ao tempo de atuação na Estratégia Saúde da Família, 04 participantes relataram menos de 1 ano, 02 entre 1 ano a 2 anos e 02 relataram estar atuando na unidade de saúde por 6 anos.

Com relação aos cursos de especializações 02 enfermeiros relataram não possuir especializações e os demais relataramos seguintes cursos: Saúde Coletiva e da Família; Gerenciamento de Unidades Básicas de Saúde e Acupuntura (Rosa); Enfermagem do Trabalho; Gestão Pública em Serviços de Saúde; Saúde da Família 
- em andamento (Marrom); Administração e Marketing em Saúde; Oncologia e Saúde da Família (Amarelo); Enfermagem do Trabalho (Verde); Residência em Saúde da Mulher (Azul); Gestão em Saúde e Obstetrícia (Laranja).

Constatou-se que 03 enfermeiros possuem mais de uma especialização e 03 enfermeiros na área de Saúde coletiva.

A educação permanente é a realização do encontro entre 0 mundo de formação e o mundo de trabalho, onde o aprender e o ensinar se incorporam ao cotidiano das organizações e ao trabalho ${ }^{10}$.

Segundo Ceccim ${ }^{11}$ a temática da educação permanente em saúde faz uma ruptura na didática geral, subvertendo as normas existentes da pedagogia tradicional. A partir do reconhecimento dos diferentes valores, saberes e desejos dos coletivos será possível entender o cotidiano como um pedaço aberto à criação de dispositivos de escuta, de decodificação do processo de trabalho e de revisão permanente.

A educação permanente em saúde constitui uma harmonia pedagógica uma vez que possibilita a problematização e a invenção de problemas. Para os serviços de saúde, esta harmonia é condição para o desenvolvimento de uma escuta qualificada, do cuidado e do tratamento. Desta forma é possível produzir conhecimento a partir das práticas referentes à intervenção/interferência, revelando a potência de cada ator na medida da sua participação no coletivo ${ }^{11}$.

\section{Capacitação sobre Educação Permanente em Saúde}

Em relação à educação permanente em saúde 03 enfermeiros não receberam capacitação sobre a temática e os demais referiram receber capacitação em várias áreas e linhas de cuidado: Capacitação sobre feridas (Rosa, Vermelho);Introdutório em Saúde da Família (Rosa, Amarelo, Vermelho);Capacitação sobre Bolsa Família (Rosa);Capacitação sobre sífilis (Rosa);Saúde Bucal (Verde); Saúde da mulher (Verde, Azul, Amarelo);Saúde Mental (Amarelo);Regulação, Controle, Avaliação e Auditoria (Amarelo, Vermelho). A carga horária do curso de capacitação destacou-se entre o tempo de 2 horas a 180 horas entre os anos de 2010 a 2015. 
A partir da década de 70, as discussões sobre a educação do trabalhador da saúde tornam-se mais significativas e passam a ser estimuladas pela OPAS com intuito de promover o desenvolvimento de pesquisas sobre a formação em serviço e as necessidades de aperfeiçoamento do trabalhador da saúde ${ }^{12}$. Segundo a portaria ํo 278 de 27 de fevereiro de 2014 onde diz que educação permanente em saúde é um "processo de aprendizado no trabalho, onde o aprender e o ensinar se incorporam ao cotidiano das organizações e ao trabalho, baseando-se na aprendizagem significativa e na possibilidade de transformar as práticas dos trabalhadores da saúde",tendo como um dos princípios da política de educação permanente em saúde a articulação entre educação e trabalho no SUS, por isso, considera-se como importante a aplicação dessa política dentro dos serviços de saúde da atenção básica, maisprecisamente nos momentos de reuniões de equipe, onde a equipe multiprofissional tem a oportunidade de dialogar, sugerir, identificar, planejar e fomentar reflexões críticas dos processos de trabalho no SUS ${ }^{3}$.

\section{A organização da Educação Permanente em Saúde na Estratégia de Saúde da Família}

A organização da Educação Permanente em Saúde (EPS) na Estratégia de Saúde da Família é realizada a partir de discussão com a equipe multiprofissional e planejamento das ações conforme a demanda dos serviços:

"Tento buscar assuntos com a própria equipe discutir nas reuniões de equipe o assunto" (Azul)

"Reuniões e discussões com equipe, rodas de conversas com o apoio do NASF, grupo de hiperdia e gestantes" (Laranja)

"Boa comunicação da equipe, reuniões, planejamentos de ações e discussões dos objetivos, apoio matricial” (Marrom).

Segundo as enfermeiras verde e amarela a organização da Educação Permanente em Saúde (EPS) ocorre de acordo com a proposta da Secretaria de 
Saúde e a enfermeira Rosa descreveu que a capacitação ocorre de acordo com os calendários do Ministério da Saúde, sendo pontual:

"Sempre organizado pela Secretaria de Saúde com o apoio de algumas instituições"(Verde).

"Através dos cronogramas propostos pela Secretaria de Saúde e coordenação da atenção básica"(Amarelo).

"Acabam sendo pontuais, aproveitando o calendário do Ministério da Saúde com as datas comemorativas, ou com alguma situação problema ocorrida na unidade de saúde"(Rosa).

A enfermeira Roxa descreveu que a Educação Permanente em Saúde (EPS) ocorre através dos grupos terapêuticos realizados pela equipe multidisciplinar da ESF:

"Através de grupos de gestantes, hiperdia, academia da saúde"(Roxo)

O entendimento da EPS como uma ação de educação em saúde também foi citado nos relatos descritos pelas enfermeiras Laranja e Vermelho. Houve a associação de educação permanente em saúde com educação em saúde/educação continuada ou ainda prevenção e promoção em saúde com sua população da área de abrangência.

As discussões a respeito de educação continuada e permanente em saúde acentuaram-se a partir do ideário da Reforma Sanitária e, com a regulamentação do SUS, por meio das Leis $8.080 / 90^{13}$ e $8.142 / 90^{14}$. A Lei 8.080/9013 propõe que cabe a área da saúde ordenar a formação de recursos humanos, atendendo as prerrogativas do artigo 200, inciso III da Constituição Federal.

O princípio teórico-metodológico da Política Nacional de Educação Permanente em Saúde (PNEPS) traz uma diferença conceitual entre educação continuada e educação permanente.

Educação Continuada: surge para capacitação dos profissionais já inseridos nos serviços. Não quer dizer que é algo perene, contínuo como sugere o 
nome, mas algo que continua a acontecer após a formação dos sujeitos. Privilegia o profissional e não apenas interesses institucionais. Tem como pressuposto 0 conhecimento para definir as práticas, objetivos, a atualização de conhecimentos específicos de uma determinada área, categoria profissional ${ }^{1}$.

Educação Permanente: o objetivo vai além da atualização do conhecimento específico de um determinado procedimento de uma determinada categoria profissional, se trabalha a transformação real das práticas, o foco é a equipe multiprofissional tanto equipe de atenção básica quanto gestores e usuáriosque possamos refletir constantemente sobre o nosso processo de trabalho, coloca em análise o alcance dos objetivos, nos faz pensar em equipe e a mudança do dia a dia de trabalho'.

Em 2003, o Ministério da Saúde criou a Secretaria de Gestão do Trabalho e da Educação na Saúde (SGTES), onde assume o compromisso de mudar e ordenar a lógica da formação dos profissionais de saúde. Se ganha um direcionamento político, com a instituição da NOB/RH para o SUS em reunião do Conselho Nacional de Saúde (Resolução CNS 330/2003). A SGTES é responsável pela elaboração das políticas orientadoras da gestão, formação, qualificação e regulação do trabalho em saúde no Brasil. Está organizada em dois departamentos: DEGES (Departamento de Gestão da Educação na Saúde) e DEGERTS (Departamento da Gestão e da Regulação do Trabalho em Saúde) ${ }^{1}$. Com a nova portaria a Política de Educação Permanente em Saúde (EPS), foi organizada por instâncias representativas e de trabalho denominadas Comissões Permanentes de Integração Ensino-Serviço (CIES) seguindo as orientações constituídas pelos antigos Pólos de Educação Permanente em Saúde e Colegiados de Secretários Municipais de Saúde. As Comissões Permanentes de Integração Ensino-Serviço (CIES) configuram-se a partir desse cenário, como uma "nova versão" dos Pólos Regionais de Educação Permanente em Saúde, atendendo o artigo 2oㅡㄹ da Portaria 1.996/2007, o qual estabelece que a condução regional da Política Nacional de Educação Permanente em Saúde ocorre por meio da Comissão Intergestora Regional (CIR), com a participação das Comissões Permanentes de Integração Ensino-Serviço (CIES) ${ }^{1}$. 
Ainda a enfermeira Vermelha destacou que atualmente não está ocorrendo à organização da Educação Permanente em Saúde (EPS): "No momento não ocorre, devido ao rodízio de funcionários, porém algum aprendizado é transmitido nos grupos de hiperdia" (Vermelha)

No SUS, os lugares de produção de cuidado são ao mesmo tempo cenários de produção pedagógica. Educar no trabalho e educar o profissional para 0 mercado de trabalho é um pressuposto da proposta da Educação Permanente em Saúde. Isso nos faz refletir que não somente à Educação fica a responsabilidade de formar cidadãos de opinião, de conhecimento técnico/científico, compete a nós, profissionais da área da saúde, gestores em nossos ambientes de trabalho tornar nosso dia a dia constante ambiente de aprendizados, uma vez que trabalho, ensino e aprendizagem misturam-se nos cenários de produção da saúde ${ }^{1}$.

\section{A participação da equipe multiprofissional da Estratégia de Saúde da Família na Educação Permanente em Saúde}

A participação da equipe multiprofissional da Estratégia de Saúde da Família na Educação Permanente em Saúde é considerada ativa e constante segundo o relato de 06 enfermeiras:

"Isso depende do município em que se está trabalhando, mas a equipe multiprofissional está presente na maioria dos momentos em que se trabalha com a educação permanente"(Azul).

"Os profissionais são escalados, liberados para participarem da educação permanente, $100 \%$ conforme a área/categoria participam em horário de serviço" (Amarelo).

"É uma participação ativa sempre que solicitada, principalmente com outros componentes fora da ESF como NASF" (Vermelho).

"A equipe participa de forma ativa, aconselhamentos de prevenção, palestras e acolhimento. Durante os grupos procuro sempre chamar alguém especial para ter uma pequena conversa com a comunidade presente (professores de 
educação física, nutricionistas, médicos, psicólogos, diversificar para poder chamar a atenção para prevenção" (Roxa).

"Participação constante, grupo bastante atuante e engajado" (Marrom).

"Todos os convidados participam"(Verde).

A enfermeira Laranja destacou que a participação da equipe multiprofissional na Educação Permanente em Saúde ocorre através de reuniões de equipe e grupos terapêuticos, com realização de palestras e rodas de discussão:"Em reuniões de hiperdia e reuniões de equipe, em meio de palestras e rodas de conversas" (Laranja).

A enfermeira roxa também ressaltou a realização de grupos terapêuticos com profissionais convidados como uma proposta de EPS.

A enfermeira verde relatou que existe pouca participação da equipe na EPS, em virtude da impossibilidade de participação de todos os profissionais; rotatividade e falta de interesse: "Pouco ativa, devido à impossibilidade de todos participarem em um mesmo momento, a rotatividade de profissionais, falta de interesse pelos temas"(Rosa).

Campos ${ }^{15}$ ressalta a importância da existência de espaços coletivos. Para este autor, um espaço coletivo é um lugar e um tempo específico, em que se dá o encontro entre sujeitos. Estes espaços são destinados à comunicação, escuta, expressão de desejos, interesses, aspectos da realidade e, também, à análise e elaboração de estratégias que se destinam à solução de necessidades. Os espaços coletivos são importantes, pois favorecem o desenvolvimento integral das pessoas, utilizando o próprio trabalho $e$ as atividades cotidianas. Com isso, superam-se iniciativas episódicas que não promovem alterações nas organizações ${ }^{15}$. Dessa forma, é preciso que os espaços coletivos se incorporem ao cotidiano dos trabalhadores de saúde, sejam em assembleias com profissionais e usuários, em reuniões ocasionais, em sessões para discussão de casos, oficinas de planejamento, entre outros.

\section{Os desafios vivenciados na organização da Educação Permanente em Saúde na Estratégia de Saúde da Família}

Revista Inova Saúde, Criciúma, vol. 8, n.2, jul. 2018.

ISSN 2317-2460 
Os principais desafios vivenciados na organização da Educação Permanente em Saúde pelas enfermeiras está relacionado à falta de tempo em desenvolver a proposta da ESP; além da resistência, falta de interesse e conhecimento sobre a importância da participação neste processo:

"Sinto falta de mais tempo para me dedicar ao estudo do que será abordado e de um momento em que isso passa ser apresentado para equipe de forma exclusiva, pois dividimos o tempo da educação permanente com as reuniões de equipe onde outros assuntos são abordados"(Rosa).

"Algumas pessoas reclamam, falam que não adianta, possuem um pouco de resistência"(Verde).

"Retirar tempo para desenvolver essas situações, visto que a rotina de uma ESF é bastante intensa. Interesse da equipe e dificuldade de ver a importância"(Azul).

"Desafio é fazer todos participarem e saberem da importância da educação permanente, só participa se tem entrega de medicamentos ou brindes"(Laranja).

"[...] a dificuldade é o tempo disponível para equilibrar com a função diária sem atraso" (Vermelho).

A Educação Permanente em Saúde é uma estratégia de transformação das práticas em saúde, sendo que em pesquisa de D'avilaet al ${ }^{16}$; Miccas; Batista; Batista $^{17}$ e Marcondes et al ${ }^{18}$ apresentaram como desafio para sua efetivação a adesão do profissional à proposta. Ainda em pesquisa de Miccas; Batista; Batista ${ }^{17}$ salientaram como fator limitante para a EPS o escasso debate em torno da integralidade do cuidado em virtude da demanda do serviço, limitação pedagógica e de recursos.

A enfermeira Vermelha também destacou a falta de tempo para desenvolver a proposta da ESP; mas citou a boa participação da equipe neste processo: "Com os profissionais de saúde há uma boa aceitação, porém a 
dificuldade é o tempo disponível para equilibrar com a função diária sem atraso"(Vermelha).

A enfermeira amarela relatou a dificuldade de liberação do profissional para participar das atividades de EPS, em virtude de excesso de trabalho e grande demanda de serviço na ESF: "Excesso de serviço/demanda diária na unidade de saúde para liberar o funcionário para participar da educação permanente" (Amarela).

Surgiram também alguns levantamentos no que diz respeito ao desinteresse, dificuldade de adesão da população com relação às atividades educativas.

"A educação em saúde para a população é de difícil alcance pelo próprio desinteresse e cultura da população [...]"(Vermelho).

"Principal dificuldade é a participação e entendimento da população que já está acostumada com o modelo curativo e não preventivo" (Roxo).

"Estabelecer critérios de seleção dos participantes, dimensionar as tarefas, pôr em prática o objetivo proposto se a equipe não se comprometer, adesão e participação da população" (Marrom).

Em pesquisa de Peres; Silva; Barba ${ }^{19}$ demonstrou o desconhecimento dos profissionais de saúde e dos gestores sobre a essência da EPS.

A qualificação da atenção à saúde está vinculada a diversos fatores, os quais incluem estruturação e organização do processo de trabalho; utilização de novas tecnologias; recursos humanos e materiais e principalmente comprometimento com o desenvolvimento da educação permanente em saúde que permita o desenvolvimento integral dos profisisonias de saúde ${ }^{20}$.

\section{Enfrentamento dos desafios vivenciados na organização da Educação Permanente em Saúde}

Para 05 enfermeiras 0 enfrentamento dos desafios e dificuldades vivenciadas na organização da Educação Permanente em Saúde (EPS) está 
associada a otimização e motivação da equipe, relataram desenvolver as ações de EPS nos momentos de reuniões de equipe.

"Otimizando a todos para participar, mostrando os benefícios de estarmos nos capacitando e atualizando para o trabalho" (Verde).

"Impondo em algumas situações, assuntos que estão em atenção. Desenvolvendo essa atividade em momentos em que a equipe já está à disposição na unidade" (Azul).

"Sobrecarregando um ou outro profissional para que outro profissional se ausente da unidade com exceção dos dias em que a unidade é fechada para reunião de equipe para ocorrer educação permanente em saúde" (Amarelo).

"Discussão dos problemas, estabelecimento de metas, motivação pessoal e organização da rotina e divulgação dos serviços, planejamento estratégico" (Marrom).

A enfermeira laranja salientou que além de enfrentar os desafios informando o agente comunitário de saúde sobre a importância de mobilizar a população também considera importante a EPS da equipe: "[...] salientando também a importância da educação permanente da equipe, para melhorar atendimento e novos conhecimentos" (Laranja)

A educação permanente possibilita que os profissionais de saúde se coloquem em análise do seu cotidiano no processo de trabalho e entendam o processo no qual estão inseridos, que repensem suas práticas e condutas, busquem novas estratégias de intervenção e superem seus medos e dificuldades tanto no individual quanto no coletivo.

De acordo com Vasconcelos; Grillo; Soares ${ }^{21}$ a proposta de educação permanente em saúde parte do reconhecimento de que é no trabalho que o profissional põe em prática a capacidade de auto avaliação, de investigação, de trabalho em equipe e de identificação da necessidade de conhecimentos complementares.

Outros desafios são enfrentados e vivenciados nas ações desenvolvidas com a comunidade, onde aparecem relatos de 03 enfermeiras que dizem 
proporcionar a população um diferencial, algo novo, que estimulem a participação ativa.

"Tentar trazer novidades a população com um diferencial e não apenas palestra, mas oferecendo algo novo estimulando o aprendizado" (Vermelho).

"Orientando e informando através das ACS sobre a importância das reuniões para os pacientes e salientando também a importância da educação permanente da equipe, para melhorar atendimento e novos conhecimentos" (Laranja).

"Procuro sempre inovar, trazer profissionais diferenciados e oferecer algo que a população busque" (Roxo).

Uma enfermeira relatou ser frustrante enfrentar esses desafios pelo excesso de demanda, de serviços burocráticos, não viabilizando a mobilização da ação no que diz respeito a Educação Permanente em Saúde (EPS).

"É frustrante, pois a correria do dia a dia e a resolução dos problemas pontuais cada vez mais tiram o foco do verdadeiro objetivo das ESF que é a promoção da saúde e prevenção das doenças" (Rosa).

A implementação de processos de ensino-aprendizagem participativos e crítico-reflexivos nos serviços de saúde é um desafio que deve ser superado diante das profundas transformações que se alcança ao modificar processos de trabalho centrado no paradigma biomédico curavista ${ }^{22}$.

\section{Sugestões ao Núcleo Educação Permanente - NEPSHU, para a otimização da Educação Permanente em Saúde na Estratégia de Saúde da Família}

Como sugestões as enfermeiras elencaram a necessidade de cronograma com temáticas para as ESF; metodologia dinâmica, participativa e com interação da equipe e da comunidade, buscando um diferencial na Educação Permanente em Saúde (EPS): 
"Cronograma para todas as unidades de saúde seguirem com temas préestabelecidoscom materiais pré elaborados que facilitem a discussão em grupo e o aprendizado" (Rosa).

"Vejo a importância do núcleo e acredito que poderiam ser instituídas as ESF um cronograma de temas que acha pertinente para que as mesmas desenvolvessem nas unidades" (Azul).

"Palestras rápidas e dinâmicas com interação entre equipes, talvez unir unidades próximas em reuniões e interação das mesmas" (Laranja).

"Um diferencial nas ações programáticas da ESF para maior participação populacional assim transmitir maiores conhecimentos" (Vermelho).

"Desenvolver um método para conscientizar a população para participação na unidade das atividades educativas e nível de prevenção" (Roxo).

"Pesquisar junto aos profissionais qual assuntos possuem interesse em estar atualizando, cursos com carga horária menor para não estender muito tempo a atualização" (Verde).

A enfermaria amarela citou como proposta que a unidade de saúde feche para que ocorra educação permanente em saúde (EPS). "Fechar a unidade de saúde para que ocorra educação permanente em saúde na ESF" (Amarelo).

Vale ressaltar que o município possui um cronograma de reuniões de equipe onde as 18 equipes de saúde da família entre as terças e sexta feiras através de um cronograma fecham por uma hora e meia para momentos de rodas de conversas, estudos de casos, educação permanente em saúde. São momentos de reflexões, de se colocar em análise com relação ao processo de trabalho, de novos aprendizados, de aperfeiçoamentos.

Conforme a portaria n. 2.488 , o profissional enfermeiro tem um papel importante a desempenhar perante a equipe no que se refere à implantação e implementação da educação permanente em saúdenas equipes de saúde de família ${ }^{23}$. Cabe ao enfermeiroordenar, construir, planejar ações no individual e no 
coletivo visando à melhoria da qualidade do atendimento e o aperfeiçoamento e a busca de novos conhecimentos da equipe multiprofissional.

A enfermeira marrom destacou a importância da inovação de propostas para os profissionais de saúde de diversas áreas, em um contexto mais amplo.

"Abrir espaço para novas propostas e opiniões dos diversos membros da área da saúde; discussão aberta de propostas ao invés de um grupo seleto de profissionais; explicitar os temas abordados" (Marrom).

A educação permanente em saúde propõe a criação de espaços coletivos com a finalidade de levar os profissionais da saúde à reflexão e avaliação do processo de trabalho, a partir da adoção de práticas de saúde e educação transformadoras ${ }^{3,22}$.

\section{CONSIDERAÇÕES FINAIS}

Por meio do presente estudo foi possível perceber a proposta da Política de Educação Permanente em Saúde (EPS) e os benefícios que ela pode trazer para as equipes de saúde da família principalmente para a população que recebe atendimento por um profissional qualificado.

Para que se consiga colocar em prática as propostas de educação permanente em saúde é preciso que haja entendimento, conhecimento dos profissionais envolvidos no processo sobre a política em questão.

Percebeu-se com a pesquisa desenvolvida que não há esse entendimento por parte das enfermeiras de como funciona o organização da educação permanente em saúde na estratégia saúde da família, houve até momentos em que educação continuada/educação em saúde foi interpretada e entendida como Educação Permanente em Saúde.

Existiram também desafios vivenciados e citados pelos participantes do estudo nos momentos de organização da educação permanente em saúde na estratégia saúde da família. A falta de tempo em desenvolver as propostas, resistência de alguns profissionais, falta de interesse e de conhecimento dos 
profissionais sobre a importância da participação neste processo foram alguns pontos relevantes.

Os dados mostram fragilidade da prática de educação permanente em saúde no cotidiano das equipes de saúde da família, muitas realizam educação permanente em saúde mediante orientação da gestão não percebendo que todos os profissionais que compõe a equipe podem estar usufruindo dos momentos de reuniões de equipe para realizar educação permanente em saúde.

Por fim os resultados aqui apresentados e analisados apontam para necessidade e continuidade do estudo com grupos mais amplos para que possamos proporcionar aos profissionais envolvidos o verdadeiro sentido da política de educação permanente em saúde fortalecendo o SUS. O profissional de saúde precisa estar preparado para atuar e transformar a realidade onde atua, tonando as unidades de saúde em um verdadeiro espaço de ensino-aprendizagem.

\section{REFERÊNCIAS}

1 Brasil. Ministério da Saúde. Portaria n. 1.996, de 20 de agosto de 2007. Dispõe sobre as diretrizes para a implementação da Política Nacional de Educação Permanente em Saúde. Brasília - DF: MS, 2007.

2 Brasil. Secretaria de Estado de Saúde de Santa Catarina. Plano Estadual de Educação Permanente em Saúde, 2011.[acesso em 2015 set. 21]. Disponível em: www.saude.sc.gov.br.

3 Brasil. Ministério da Saúde. Portaria n. 278, de 27 de fevereiro de 2014.Institui diretrizes para implementação da Política de Educação Permanente em Saúde, no âmbito do Ministério da Saúde (MS).Brasília - DF: MS, 2014.

4 Ceccim RB, Ferla AA. Educação Permanente.In: Estágio de Vivência no SUS: o cotidiano do SUS enquanto Principio Educativo. Salvador, 2009, p. 70-75.

5 Brasil. Ministério da Saúde. Humaniza SUS. Política Nacional de Humanização.A Humanização como Eixo Norteador das Práticas de Atenção e Gestão em Todas as Instâncias do SUS. Brasília - DF: MS, 2004. 
6 Içara. Secretaria Municipal de Administração. Decreto no 180 de 23 de outubro de 2014. Institui o Núcleo de Educação Permanente em Saúde e Humanização. Içara SC, 2014.

7 Brasil. Conselho Nacional de Saúde. Resolução ํㅜ 510, de 07 de abril de 2016.[acesso em 2016 out. 30]. Disponível em: http://conselho.saude.gov.br/resolucoes/2016/Reso510.pdf.

8 LeopardiMT. Metodologia da Pesquisa na Saúde. Florianópolis: UFSC, 2002. 294 p.

9 Minayo MCS. Pesquisa social: teoria, método e criatividade. 28 ed. Petrópolis, RJ: Vozes, 2009. $108 \mathrm{p}$.

10 Crivelaro JLG, Morais MEP, PaeseAPF. Educação Permanente em Saúde. Escola de Enfermagem, Uniandrade, 2007.

11 Ceccim RB. Réplica. Interface(Botucatu). 2005; 9(16): 175-177.

12 Lopes SRS, Piovesan ETA, Melo LO, Pereira MF.Potencialidades da educação permanente para a transformação das práticas de saúde.Com. Ciências Saúde. 2007; 18(2):147-155 1

13 Brasil. Constituição Federal. Lei no 8.080, de 19 de setembro de 1990. Dispõe sobre as condições para a promoção, proteção e recuperação da saúde, a organização e o funcionamento dos serviços correspondentes e dá outras providências.Brasília - DF, 1990.

14 Brasil. Constituição Federal. Lei no 8.142, de 28 de dezembro de 1990.Dispõe sobre a participação da comunidade na gestão do Sistema Único de Saúde (SUS\} e sobre as transferências intergovernamentais de recursos financeiros na área da saúde e dá outras providências.Brasília - DF, 1990.

15 Campos GWS. Um método para análise e co-gestão de coletivos: a constituição do sujeito, a produção de valor de uso e a democracia em instituições: o método da roda. São Paulo: Hucitec, 2000.

16 D'Avila LS, Assis LN, Melo MB, Brant LC. Adesao ao Programa de Educacao Permanente para medicos de familia de um Estado da Regiao Sudeste do Brasil. Ciênc. saúde coletiva. 2014 fev.; 19(2): 401-416. 
17 Miccas FL, Batista SHS. Educação permanente em saúde: metassíntese. Rev. Saúde Pública. 2014 fev.; 48(1): 170-185.

18 Marcondes FL, Fonseca PIMN, Silveira PG, Tavares CMM. Desvelando os sentidos da educação permanente em um programa municipal: estudo sociopoético. Journal Health NPEPS. 2016; 1(1):40-52.

19 Peres C, Silva RF, Barba PCSD. Desafios e potencialidades do processo de educação permanente em saúde. Trab. educ. saúde. 2016; 14(3), 783-801.

20 Silva LAA, Schmidt SMS, Noal HC, Signor E, Gomes IEM. Avaliação da educação permanente no processo de trabalho em saúde. Trab. educ. saúde. 2016; 14(3), 765-781

21 Vasconcelos M, Grillo MJC, Soares SM. Práticas educativas em Atenção Básica à Saúde. Tecnologias para abordagem ao indivíduo, família e comunidade. Unidade Didática I. Organização do processo de trabalho na Atenção Básica à Saúde. Módulo 4. Belo Horizonte: UFMG, 2009. 76 p.

22 Andrade RS, Caldas LBSN, Falcão MLP, Góes PSA. Processo de Trabalho em Unidade de Saúde da Família e a Educação Permanente. Trab. educ. saúde. 2016; 14(2), 505-521.

23 Brasil. Ministério da Saúde. Política Nacional de Atenção Básica. Portaria n. 2.488 de 21 de outubro de 2011. Brasília - DF: MS, 2011. 